\title{
Prevalence of Serum Antibodies against Six Leptospira Serovars in Buffaloes in Tabriz, Northwestern Iran
}

\author{
Tolouei Mohammad
}

\author{
Department of Clinical Sciences, Faculty of Veterinary Medicine, University of Tabriz, Iran
}

\begin{abstract}
Leptospirosis is an important zoonotic infectious and its prevalence is unknown in buffalo in Iran particularly in Tabriz, northwest of the country. To survey the prevalence of Leptospira infection in buffaloes in Tabriz, blood samples were collected from 85 female buffaloes slaughtered in Tabriz industrial slaughterhouse from December 2008 to November 2009. Sera were stored at $-20^{\circ} \mathrm{C}$ until they were examined. Sera were initially screened at serum dilution of 1:100 against six live antigens of Leptospira interrogans, Pomona, Canicola, Hardjo, Ballum, Icterohaemorrhagiae and Grippotyphosa by using the microscopic agglutination test (MAT). The samples were considered positive if $50 \%$ or more of agglutination of leptospire in a dilution tests serum of I:100 were observed. 30 serums $(35.29 \%)$ at dilution 1:100 were positive against 1 or 2 of serovars. the highest prevalent serovar in buffalo was Grippotyphosa (51.3\%), and fallowed whit Pomona (29.7\%), canicola (10.8\%) and Icterohaemorrhagiae $(8.1 \%)$. All of the samples were seronegative for serovar Ballum and Hardjo. Statistical analysis of the results showed that the rates of the infection in the autumn-winter and spring-summer didn't have significant difference $(p>0 / 05)$. The rate of the infection has been statistically increased with the aging $(p<0 / 05)$ and the animals with 3 and 4 pair's permanent teeth had the highest infection rates. The serological infection rate in buffaloes in Tabriz is relatively high and it appears that it is because of living type of buffaloes in water and swamp, thus consequently the preventive methods must be applied to control of the disease.
\end{abstract}

Keywords: Leptospirosis, seroprevalence, buffalo, MAT, Tabriz.

INTRODUCTION

Leptospirosis is an important infectious disease of livestock animals and humans. It is caused by the pathogenic Leptospira interrogans that contains over 212 serovars. This infection has a worldwide distribution [1]. The distribution and the prevalence of serovars vary based on the geographical regions and depend on environmental and host factors. The main source of the pathogenic leptospira serovars is an infected animal that contaminates pasture, drinking water and feed by infective urine, aborted fetuses and uterine discharges [2,3]. Some clinical signs of the infected buffalos include fever, abortion, and a reduction in milk yield, icterus and repeat breeding [4]. The wallowing behavior of the buffaloes makes them susceptible to leptospirosis because the water sources are often contaminated by rodents and wild animals. These animals are natural carriers of the leptospira serovars [5]. Based on the fact that the infection is usually developed by the native serovars, identification of these serovars in each area is very critical in epidemiology of the infection in the same area [6]. Urine is the main source of infection since the infected animals may shed leptospirae in their urine for long time even after clinical recovery therefore act as potential carriers [3].

*Address correspondence to this author at the Department of Clinical Sciences, Faculty of Veterinary Medicine, University of Tabriz, Iran; Tel: +989141080928; Fax: +984116378734; E-mail: mtooloei@tabrizu.ac.ir
Leptospirosis is categorized into two broad categories: host-adapted and non-host adapted. An infected animal with a host-adapted serovar is a potential maintenance or reservoir host. Cattle are the maintenance host for some serovars. As a result, different serological surveys conducted on cattle worldwide have revealed that relatively high percentages of the sera had antibodies against a large number of leptospiral serovars $[1,7]$. According to the high leptospiral seroprevalence rates in cattle in previous studies reported from Iran and particularly the East Azarbaijan province [8-10], and based on the fact that buffaloes are usually in contact with cattle directly or indirectly in the most regions of the province, it is predicted that buffalo may be one of the important animals in epidemiology of the infection in province. Prevalence of leptospiral infection in buffalo has been unknown in Tabriz so far. The goals of the presented survey was to determine the seroprevalence of the leptospiral infection, determine the titer of the antibodies against different Leptospira serovars and evaluate the relationship between seroprevalence and animal and environmental factors in buffaloes slaughtered in Tabriz, Iran.

\section{MATERIALS AND METHODS}

\section{Animals and Samples}

Blood samples were stratified randomly taken from 85 buffalo slaughtered in industrial slaughterhouse of Tabriz from December 2008 to November 2009. Ten 
milliliter of the blood samples were collected from jugular vein of each buffaloes.

None of the animals had been vaccinated against leptospirae. The animals were categorized to 5 age groups, without permanent teeth and with 1, 2, 3 and 4 pair's permanent teeth. At the time of the sampling, all the animals hadn't any clinical signs suggestive of leptospirosis.

\section{Serology}

The blood samples were allowed to clot and centrifuged for $10 \mathrm{~min}$ at $2500 \times \mathrm{g}$; after centrifugation, the serum was harvested and stored at $-20^{\circ} \mathrm{C}$ until examination time. The sera were tested for antibodies to six live antigens of leptospira interrogans ( $L$. interrogans serovar Grippotyphosa, Icterohaemorrhagiae, Hardjo, Pomona, Canicola and Ballum) with regarding to the previous surveys in Iran, using Microscopic Agglutination Test (MAT) in leptospiral research laboratory. EMJH- base $23 \%$ solutions used for preparing the different dilutions of sera (1:50 to $1: 800)$. Sufficient quantities of the 7-10 days old pure leptospira cultures were being used as antigen. The MAT was performed according to the methods of [11]: sera were initially screened at a dilution of $1: 100$ against antigens. At first, a serum dilution at 1:50 was made and then equal volume to the diluted serum of each antigen was added to each wells of micro-titration plate, to make the final serum dilution of $1: 100$. The micro-titration plates were incubated at $29^{\circ} \mathrm{C}$ for $2 \mathrm{~h}$.
Then the plates were examined using dark-field microscop. Results were deemed to be positive when $50 \%$ or more of agglutination of leptospires at serum dilution of 1:100 was observed [11]. Sera with positive results were titrated against reacting antigens in serial 2-fold dilutions from 1:100 to 1:800.

\section{Statistical Analysis}

Results were statistically analyzed by using the software SPSS 14.5 with the aid of Chi-Square and Fisher's exact tests with $95 \%$ confidence interval to determine the association between the infection rates and age and season.

\section{RESULTS}

Antibody prevalence's, as determined by positive results at a 1:100 dilution or more, against one or more serovars was $35.29 \%(30 / 85)$ (Table $\mathbf{1})$.

\section{Results of MAT}

The largest number of reactors was for serovar Grippotyphosa 51.3\% (19/37) then followed by Pomona $29.7 \% \quad(11 / 37)$, Canicola $10.8 \% \quad(4 / 37)$, Icterohaemorrhagiae $8.1 \%$ (3/37). Antibody against more than one serovar were found in seven (33.3\%) sera of seropositive animals, so that mixed infection of Grippotyphosa and Pomona, Grippotyphosa and Canicola and Pomona and Icterohaemorrhagiae were seen in 4, 2 and 1 infected buffaloes, respectively. All

Table 1: Seroprevalence of Leptospirosis in Female Buffaloes Slaughtered in Tabriz Industrial Abattoir-Iran

\begin{tabular}{|c|c|c|c|}
\hline & No. of tested & No. of positive ${ }^{\text {a }}(\mathbf{f})$ & Prevalence (\%) \\
\hline \hline Serum & 85 & 30 & 35.29 \\
\hline
\end{tabular}

${ }^{a}$ Results of MAT.

Table 2: Distribution of Serovars Specific Antileptospiral Antibodies and their Titration in Seropositive Female Buffaloes

\begin{tabular}{|c|c|c|c|c|}
\hline Serovar & $1: 100$ & 1:200 & $1: 400$ & Total \\
\hline Grippotyphosa & 11 & 7 & 1 & $19(51.3)$ \\
\hline Canicola & 3 & 3 & 0 & $4(10.8)$ \\
\hline Pomona & 7 & 3 & 1 & $11(29.7)$ \\
\hline Icterohaemorrhagiae & 3 & 0 & 0 & $3(8.1)$ \\
\hline Hardjo & 0 & 0 & 0 & 0 \\
\hline Ballum & 0 & 0 & 0 & 0 \\
\hline Total & $24(64.8)$ & $11(29.7)$ & $2(5.4)$ & $37(100)$ \\
\hline
\end{tabular}


Table 3: Seropositivity for Leptospirosis in the Slaughtered Female Buffaloes According to the Season of Sampling

\begin{tabular}{|c|c|c|c|}
\hline Season & No. of tested & No. of positive (f) & Prevalence (\%) \\
\hline \hline Winter-autumn & 54 & 18 & 33.3 \\
\hline spring-Summer & 31 & 12 & 38.7 \\
\hline Total & 85 & 30 & 35.2 \\
\hline
\end{tabular}

Statistical analysis: $p>0 / 05$.

Table 4: Seropositivity for Leptospirosis in the Slaughtered Female Buffaloes According to Age

\begin{tabular}{|c|c|c|c|}
\hline Variable & No. of tested & No. of positive (f) & Prevalence (\%) \\
\hline \multicolumn{4}{|c|}{ Age (pairs of permanent teeth) } \\
\hline 0 & 0 & 0 & 0 \\
\hline 1 & 3 & 0 & 0 \\
\hline 2 & 12 & 3 & 25 \\
\hline 3 & 43 & 18 & 41.8 \\
\hline 4 & 27 & 9 & 33.3 \\
\hline Total & 85 & 30 & 35.2 \\
\hline
\end{tabular}

of the samples were negative against serovar Ballum and Hardjo.

There are 37 recognizable Antibody titers from the all of 30 seropositive samples. The majority of titre levels were 1:100 for all serovars and the frequency of $1: 100,1: 200$ and 1:400 dilutions were $64.8 \%(24 / 37)$, $29.7 \%(11 / 37)$ and $5.4 \%(2 / 37)$, respectively (Table 2$)$.

Statistical analysis of the results revealed that the rates of the infection in the autumn -winter (33.3\%) and spring -summer $(38.8 \%)$ don't have significant difference and distribution of the infection not dependent to vary seasons (Table 3 ).

The infection rate has been statistically increased with the aging $(p<0 / 05)$ and the animals with 3 and 4 pair's permanent teeth (5-6 years old) had the highest infection rates (Table 4).

\section{DISCUSSION}

Buffalo is a native animal of Iran with a total population of 500000 . More than 80 percent of the population of bufalo is in the north and northwest (Azerbaijan province) and 18 percent in the south of the country. Buffalo are important carriers and shedders of leptospires. The infected buffalo are a potential danger to human zoonoses for instence slaughterhouse workers, farmers and buffalo Scherer [5]. Epidemiological studies in different countries have shown that leptospirosis has been occurring in buffalo (Bosbubalis) and reported both clinical and subclinical infections [12-16]. In Iran, the first study of leptospirosis prevalence in buffaloes was carried out in Ahvaz [4]. Also one case of leptospirosis was reported in buffaloes in east Azarbaijan province [9]. However, no previous study of the seroprevalence of leptospiral in buffaloes has been attempted in Tabriz.

MAT is common test used for the seroprevalence survey of leptospirosis. Buffaloes are training in rural condition in this region and have great contact with cattle. Actually some farmers keep buffalo and cattle in the same barn. Cattle are maintenance host for many serotypes of the leptospirae and previous studies have demonstrated relatively high prevalence of infection in cattle in Iran and other countries. Seroprevalences of leptospiral infections in cattle in Tehran suburb dairy farms were $31.2 \%$ [17] and 46.8\% [18] in 1990 and 2001 respectively. Seroprevalence of leptospiral infections in cattle in Mashhad suburb (north east of Iran) was 19.15\% in 2011 [19] and in East Azarbaijan province (north west of the country) were $48.5 \%$ [10] and 24\% [9] in 1993 and 2007 respectively.

In the present study, prevalence of leptospirosis was $35.29 \%$ in female buffaloes in Tabriz. The reported results confirmed that prevalence of leptospiral bug in buffalo is different not only between countries but also between different areas of each country. These differences may be the result of environmental factors. 
It has been found that environmental factors influence the development of Leptospira infection in animals and humans. Long term survival of pathogenic leptospires outside the host requires a warm and moist environment with a neutral $\mathrm{pH}$. Significant variation in the survival rate of various serovars is based on the $\mathrm{pH}$ of soil or water. Areas with high rainfall and subsurface water and land in the close to the equator are enzootic zones [20]. The seroprevalence of leptospiral infection in buffalo has been reported to be $1.1 \%$ and $12.22 \%$ in India [21,22], $17 \%$ in Bulgaria [23], 5.8\% and $82.9 \%$ in Brazil [24,25], 31\% in Malaysia [26], $0.5 \%$ in Indonesia [27], 33.4\% in Egypt [28], 11.3\% in Dagestan [29], $41.93 \%$ in Seri Lanka [30], 67\% in Italy [15], and 30\% and $58.73 \%$ in west of Iran [4,31]. The results obtained from of the present study showed that the serological infection rate in buffaloes is relatively high in Tabriz. Consequently, prevention methods must be applied to prevent the spread of the disease and its transmission to humans and other animals.

In contrast to previous studies in Tabriz, the prevalence of antibodies to one or more serovars of $L$. interrogans was $48.5 \%$ [10] and $24 \%$ [9] in cattle, $18.4 \%$ in sheep [32] and $41.05 \%$ in horses [33]. Although, the significance of these differences was not defined, it may be related to the differences in susceptibility of these animals. This study showed that the seroprevalence of leptospirosis is quite high. As the buffalo breed naturally most of the time, hence venereal transmission should be considered a contributing factor. In addition, buffalo adapted to live in water and marsh, in this situation transmission appears to be faster and more extensive, as this could increase the chances for contact of infected water with mucous membranes like eyes, nose, and mouth. Based on these reasons, buffaloes have a greater chance of being exposed to Leptospira naturally.

In this study Grippotyphosa and Pomona were detected as the most prevalent serovars with 51.3 and $29.7 \%$ of occurance, respectively. According to the fact that the rodents are the most important maintenance hosts for Grippotyphosa and Pomona [1] and considering the repeated contacts between buffaloes and these animals, the relatively high prevalence of these serovars are justified in this study.

In previous studies in Tabriz and Ahvaz, the main serovars were Pomona and Grippotyphosa in cattle, Pomona in horses $[9,33]$ and Grippotyphosa in sheep [32] in Tabriz, and were canicola and Pomona [4,34] in buffaloes and cattle of Ahvaz, respectively. It is probable that these serovars may be adapted to and maintained by these farm animals in Tabriz.

The major serovar that gives rise to serological reaction in buffaloes varies in different countries. For instance: Pomona (45.08\%) in India [22], Pomona (57\%) in Bulgaria [23], Hardjo (85.4\%) in Egypt [28], Hebdomadis (56.4\%) in Dagestan [29], Weerasingha $(30.2 \%)$ in Sri Lanka [30], and Icterohaemorrhagiae $(21 \%)$ in Pakistan [27] were most common serovars in buffalo.

In addition, one serovar may be predominant in a country but none of the animals may be affected by this serovar in another country. This emphasizes the need to promote regional surveys for leptospirosis, as hostparasite relationship may change depending on the ecology of the region [32].

In serologic tests of leptospirosis such as MAT, the results often indicate an infection by more than one serovar $[4,8,32,35]$. This is probably the outcome of a mixed infection serotype, but the existence of crossreactivity in the MAT among serotypes is well known and can not be excluded from this interpretation [4,32].

The high prevalence of infection and dominant titre of $1: 100$ show that leptospiral infection in buffaloes is endemic in Tabriz.

Statistical analysis of the results showed that the rates of the infection in the autumn-winter (33.3\%) and spring-summer (38.8\%) have no significant difference. It can be due to wallowing habit of buffaloes that they tend to moist and bog situation in all seasons.

The rate of the infection has been statistically increased with the aging $(p<0 / 05)$ and the animals with three and four pair's permanent teeth (4-5 years old) had the highest infection rates. This finding confirms the results of the other surveys. In conclusion, the prevalence is increasing as the aging due to the improvement of the probability of contact of animals with organism $[32,36,37]$. Although the conducted study in Ahvaz showed no relationship between age of buffalo and infection [4].

\section{CONCLUSION}

The serological infection rate among buffalo is relatively high in Tabriz and it seems that this is because of the living type of buffalo in the water and marshes. Therefore, preventive methods should be applied to control the infection. 


\section{ACKNOWLEDGEMENT}

The authors would like to thank the Research Vice Chancellors of University of Tabriz for financial support of this project.

\section{REFERENCES}

[1] Radostitis OM, Gay CC, Hinchcliff KH, Constable PD. Veterinary Medicine. $10^{\text {th }}$ Ed. London: Saunders Elsevier 2007, p. 971-985.

[2] Carter GR, Chengappa MM. Essential of Veterinary Bacteriology and Mycology. $4^{\text {th }}$ Ed. Lea and Febiger1991, p. 220-223.

[3] Quinn PJ, Markey BK, Carter ME, Donnelly WJ, Leonard FC. Veterinary Microbiology and Microbial Disease. Blackwell 2002, p. 175-184, 453-455, 484.

[4] Hajikolaei MR, Ghorbanpour M, Abdollapour GR. Seroprevalence of leptospiral infection in buffalo (Bubalusubalis). Bull Vet Inst Pulawy 2006; 50: 341-344.

[5] FAO. FAO Regional Office For Europe Inter-Regional Cooperative Research Network On Buffalo Edit bye Borghese, A.: Buffalo production and research, Chapter I, Mediterranean area, Istituto Sperimentale per la Zootecnia Via Salaria, 31 - 00016 Monterotondo, Roma (Italy): 2005, 22 and 277.

[6] Cerri D, Ebani V, Pedrini A, Andreani E, Farina R, Pinzauti P. Epidemiology of leptospirosis: Observations on serological data obtained by a diagnostic laboratory for leptospirosis from 1995 to 2001. New Microbiol 2003; 26 (4): 383-389.

[7] Bulu AA, Dorterler R, Ozkan O, Hasturk F. The studies on the spreading and the serotype of leptospirosis occurrence in cattle and sheep in some cities of the East Anatolia. J Etlik Vet Microbiol 1990; 6: 49-60.

[8] Firouzi R, Vandyousefi J. A serological survey on bovine leptospirosis in Shiraz. Iranian J Vet Res 2000; 2: 118-123.

[9] Hasanpour A, Fartashvand M, Abdollapour GR, Mogadam G, Nadalian MG, Sattari S. Seroprevalence of leptospiral infection in dairy herds in Tabriz- Iran. J Res Reconstruct 2007; 74: 67-77.

[10] Shoaei S. Serologic study on leptospiral infection in cattle in East Azarbaijanprovience. Thesis for graduation in DVM Degree, Azad University of Tabriz 1993, No. of thesis: 20.

[11] OIE. Manual of standards diagnostic tests and vaccines, leptospirosis, Paris. Part 2, Section 2.2, Chapter 2.2.4. 2000, http://www.OlE.int.

[12] Kujumgiev D. La leptospirosis dei bufali. Veterinar Italiano 1963; 10: 790

[13] Arora BM, Baxi KK. A note on the sero-evidence of leptospiral antibodies in domestic animals in Punjab State. Indian J Anim Sci 1978; 48: 836-838.

[14] Farina R. Microbiologia Medica 1989; 4: 87

[15] Ciceroni L, D’Aniello P, Russo N, Picarella D, Nese D, Lauria F, Pinto A, Cacciapuoti B. Prevalence of leptospire infections in buffalo herds in Italy. Vet Rec 1995; 137: 192-193. http://dx.doi.org/10.1136/vr.137.8.192

[16] Selvaraj J, Murali Manohar B, Govindarajan R, VajiraveluJayakumar D, Meenambigai TV, Balachandran C. Seroprevalence of leptospirosis in She- buffaloes (Bosbubalis) at slaughter in Chennai, India. Buffalo Bull 2010; 29(2): 95-97.

[17] Moharamie M. Seroepidemiologic study on leptospiral infection in cattle in Tehran. Thesis for graduation in DVM Degree, University of Tehran. 1990, No. of thesis: 1928.
Golie, G., Seroepidemiologic study on leptospiral infection in cattle in Karaj. Thesis for graduation in DVM Degree, University of Tehran. 2001, No. of thesis: 17T.

[19] Tabatabaeizadeh E, HashemiTabar G, Farzaneh N, Seifi HA Prevalence of Leptospirahardjo antibody in bulk tank milk in some dairy herds in Mashhad suburb. African $\mathrm{J}$ Microbiol Res 2011; 5(14): 1768-1772.

[20] Miller DA, Wilson MA, Beran GW. Relationship between prevalence of Leptospirainterrogans in cattle, and regional, climatic, and seasonal factors. Am J Vet Res 1991; 52: 1761768.

[21] Hussain J, Khader TGA, John M. A survey on the incidence of leptospirosis among domestic animals in and around Madras City. Livestock Adviser Bangalore 1981; 6: 45-47.

[22] Rao AS, Keshavamurthy BS. Serological evidence of leptospiral infection in buffaloes. Indian J Comp Microbiol Immunol Infect Dis 1982; 3: 147-152.

[23] Khalacheva M, Sherkov SH. Outbreak of leptospirosis among buffaloes in Bulgaria. Veterinarina - Sbirka 1981; 79: 33-36.

[24] Moreira-Caldas E, Tishcenko L M, Pereira-Filho M, QuerinoCamara J, Barreto-Sampaio M, Bernardo-da- Cunha J. Antileptospiral agglutinins in animal blood serum from Bahia State, Brazil (cattle, swine, goat, buffalo, horse, dog). Arquivos da Escola de Medicina Veterinaria da Universidade Federal da Bahia 1977; 2: 83-98.

[25] Sandoval LA, Arruda NM, Teruya JM, Giorgi W, Amaral LBS, Mazanti MT, De-Arruda NM. Study of buffaloes: prevalence of brucellosis and leptospirosis in Sao Paulo State, Brazil. Biologico 1979; 45: 209-212.

[26] Bahaman AR, Ibrahim AL, Adam H. Serological prevalence of leptospiral infection in domestic animals in West Malaysia. Epidemiol Infect 1987; 99: 379-392. http://dx.doi.org/10.1017/S0950268800067868

[27] Chaudhry JI, Khan MA, Akhtar T, Khan AG, Chaudhry MS Seroprevalence of leptospirosis in buffaloes. Buffalo J 1996; 12: 65-71.

[28] Tawfik MS. Leptospirosis in Egypt. II. Leptospiral agglutinins of serotype hardjo and pomona in Egyptian cattle and buffaloes. J Egypt Vet Med Assoc 1977; 37: 121-128.

[29] Akhmedov MM, Amaev KG, Salikhov S, Makhmudov MP Epidemiology of leptospirosis in animals (cattle, buffalo, horse, sheep, swine and dog) in Dagestan. Veterinariya (Moscow) 1979; 1: 42-43.

[30] Wijewardana TG, Wijewardana BDR, Appuhamy WNDGS, Premaratna KRVPM, Perera BMAO, Siriwardene JAdeS, Horadagoda NU, Ibrahim MNM. Prevalence of leptospiral antibodies in buffaloes in Sri Lanka. In: Proceedings on the Role of the Buffalo in Rural Development in Asia, 1995. p. 415-426.

[31] Vand-Yousefi J, Azarvandi AR, Moradi S, Safavie S, Khaki P. Leptospirosis in buffalo. In: Proceedings of the first National Congress on Buffalo Diseases in Iran, Ahvaz, Iran, 1998. p. 66.

[32] Tooloei M, Abdollapour G, Karimi H, Hasanpor A. Prevalence of Serum Antibodies Against Six LeptospiraSerovars in Sheep in Tabriz, Northwestern Iran. J Anim Vet Advan 2008; 7(4): 450-455.

[33] Hassanpour A, Monfared N, Abdollahpour GR, Satari S Seroprevalence of leptospiral infection in horses in TabrizIran. J Bacteriol Res 2009; 1(8): 97-100.

[34] Hajikolaei MR, Ghorbanpour M, Gharibi D, Abdollapour GR Serologic study on leptospiral infection in sheep in Ahvaz, southwestern Iran. Iranian J Vet Res 2007; 8 (4)21: 333-336.

[35] Hathaway SC, Little TWA, Finch SM, Stevens AE. Leptospiral infection in horses in England: A serological study. Vet Rec 1981; 2: 396-398.

http://dx.doi.org/10.1136/vr.108.18.396 
[36] Ciceroni L, Lombardo D, Pinto A, Ciarrocchi S, Simeoni J. Prevalence of antibodies to Leptospiraserovars in sheep and goats in Alto Adige-South Tyrol. J Vet Med 2000; 47 (3): 217223.

http://dx.doi.org/10.1046/j.1439-0450.2000.00333.x
[37] Saglam YS, Yener Z, Temur A, Yalcin E. Immunohistochemical detection of leptospiral antigens in cases of naturally occurring abortion in sheep. Small Rum Res 2008; 74(1-3): 119-122.

http://dx.doi.org/10.1016/j.smallrumres.2007.04.006 